\title{
BEDA EFEKTIFITAS METODE BUGNET EXERCISE DENGAN METODE WILLIAM FLEKSION EXERCISE PADA PASIEN \\ NYERI PINGGANG BAWAH DI KLINIK FISIOTERAPI RATULANGI MEDICAL CENTRE MAKASSAR
}

\author{
Suharto, Arpanjam'an, Suriani \\ Jurusan Fisioterapi Politeknik Kesehatan Makassar
}

\begin{abstract}
ABSTRAK
Low back pain is a common complaint in everyday practice. It is estimated that almost everyone has experienced low back pain during his lifetime. The cause of low back pain is very diverse from mild to severe and very serious. In Indonesia, lower back pain is found at the age of 40 years. In developed countries the prevalence of low back pain is about $70-80 \%$. Although rarely fatal but the perceived pain causes the patient to experience limitations in daily activities and many loss of working hours, especially in the productive age, so that is the most reason in seeking treatment.This study aims to determine the Differences Effectiveness between Bugnet Exercise method with William Fleksion Exercise method on the application of Infra Red Rays Patients with Lower Waist Pain with quasi experimental and pre-test research design - post test two groups of 20 people each method 10 research subjects randomly Sampling. Both groups were measured by using Visual analog scale before and after treatment. The results of the study were 50\% aged 31-40 and 50\% aged 41-60 years. In the research subjects given IRR and Bugnet exercises obtained p value $=0.000$. While given IRR and William flexion exercises obtained $\mathrm{p}$ value $=0.005$. In the Mann Whitney Test test, $\mathrm{p}=0.052>\alpha=0.05$, which means there is no significant difference between the two methods to decrease the actuality of lower back pain but IRR with William flexion exercises has a greater mean value of change that is $3,350 \pm 0.66841 \mathrm{~cm}$ than the group IRR treatment with Bugnet Exercise method is $3,300 \pm 0.66173 \mathrm{~cm}$. It was concluded that IRR with William flexion exercises better results in decreased pain in patients with lower back pain.
\end{abstract}

Keywords: Bugnet exercises, William flexion, Lower back pain

\section{Latar Belakang Masalah}

Nyeri pinggang bawah merupakan keluhan yang sering dijumpai di praktek sehari-hari. Diperkirakan hampir semua orang pernah mengalami nyeri pinggang bawah semasa hidupnya. Penyebab nyeri pinggang bawah sangat beraneka ragam dari yang ringan sampai yang berat dan sangat serius.

Di Indonesia, nyeri pinggang bawah dijumpai pada golongan usia 40 tahun. Pada negara maju prevalensi orang terkena nyeri pinggang bawah adalah sekitar 70-80 Walaupun jarang fatal namun nyeri yang dirasakan menyebabkan penderita mengalami keterbatasan dalam aktifitas sehari-hari dan banyak kehilangan jam kerja terutama pada usia produktif, sehingga merupakan alasan terbanyak dalam mencari pengobatan.

Kemampuan fungsional seseorang sangat berkaitan dengan perkembangan fisik, sosial, emosional, dan mental. Secara umum, fungsi merupakan aktivitas alamiah, yang dibutuhkan atau yang diharapkan dari seseorang. Fungsi sangat berkaitan dengan sehat, dimana secara khusus sehat menunjukkan kemampuan seseorang untuk menyelesaikan dengan baik tugas-tugas yang diharapkan dalam lingkungannya, sehingga tanpa kemampuan fungsional maka seseorang akan sulit untuk menyelesaikan tugas-tugasnya.

Nyeri Pinggang Bawah merupakan kondisi yang sangat kompleks karena dapat disebabkan oleh berbagai penyebab seperti trauma, kejadian non-traumatik yang tidak diketahui (degenerasi, tumor, infeksi, dll), dan gangguan pada organ viscera juga dapat menimbulkan low back pain.

Nyeri Pinggang Bawah sering terjadi pada berbagai populasi seperti pekerja/karyawan kantor, ibu rumah tangga, dan pejabat. Hal ini disebabkan karena regio lumbal sering terlibat dalam aktivitas pekerjaan, olahraga, dan sikap tubuh. Otototot yang menstabilisasi regio lumbal sering mengalami gangguan akibat stress mekanikal yang terjadi secara berulangulang. Namun demikian, sumber dan penyebab yang paling banyak adalah gangguan akibat faktor mekanik (mechanical back pain), dan trauma.

Nyeri Pinggang Bawah merupakan gangguan muskuloskeletal yang banyak dialami oleh populasi usia muda dan dewasa. Sekitar 50\% dari seluruh populasi yang mengalami gangguan muskuloskeletal adalah nyeri pinggang bawah. Prevalensi ketidakmampuan beraktivitas akibat low back pain (LBP) meningkat sejalan dengan bertambahnya usia yaitu sekitar $60 \%$ pada wanita dan $40 \%$ pada laki-laki (Navid, 2009). 
Menurut Cailliet (1991), kira-kira $80 \%$ setiap orang dalam hidupnya pernah mengalami nyeri pinggang bawah, tanpa mengenal perbedaan jenis kelamin, tingkat sosial atau tingkat pendidikan, dan salah satu penyebabnya ialah kebiasaan duduk dengan posisi yang kurang benar..

Nyeri pinggang bawah menghilangkan banyak jam kerja dan membutuhkan banyak biaya untuk penyembuhannya. Haanen et.all (dalam Suharto 2001), yang meneliti 3000 pria dan 3500 perempuan usia 20 tahun ke atas menyatakan bahwa $51 \%$ pria dan $57 \%$ wanita mengeluh nyeri pinggang bawah dan $50 \%$ tidak bugar untuk bekerja selama beberapa waktu dan $8 \%$ harus alih pekerjaan.

Menurut Anthony H. Wheeler (2007), sekitar $80 \%$ penduduk Amerika mengalami Nyeri Pinggang Bawah. Diperkirakan sekitar $15-20 \%$ berkembang nyeri menjalar, dan sekitar 2 - 8\% nyeri kronik. Setiap tahun, sekitar 3 - 4\% dari populasi nyeri pinggang bawah mengalami ketidakmampuan dalam aktivitas (disability). Sedangkan insiden low back pain (LBP) mencapai puncaknya pada usia pertengahan dan menurun pada usia tua.

Untuk mengobati penderita nyeri pinggang bawah fisioterapis dapat memberikan berbagai macam metode pengobatan diantaranya interferensi, microwave diathermy, latihan stabilisasi, metode william fleksion exercises, metode Mc.Kenzi exercises, Metode Bugnet exercises dan metode stretching. Dengan banyaknya metode pengobatan untuk nyeri pinggang bawah, maka perlu dilakukan suatu penelitian untuk melihat metode mana yang lebih efektif antara metode bugnet exercise dan william fleksion exercises pada penderita nyeri pinggang bawah di Klinik Fisioterapi Ratulangi Medical Centre Makassar.

\section{Tujuan Penelitian}

Untuk mengetahui perbedaan efektifitas antara Bugnet exercise dan William Flekson exercise pada penderita nyeri pinggang bawah

\section{Metode Penelitian}

\section{Disain Penelitian}

Jenis penelitian ini adalah quasi experiment dengan desain pre test - post test two group design.

\section{Tempat dan waktu penelitian}

Penelitian dilakukan di Klinik

Fisioterapi Ratulangi Medical Centre

Makassar dari bulan Juli sampai dengan

Oktober 2015.

\section{Populasi}

Populasi penelitian adalah semua penderita nyeri pinggang bawah yang berkunjung ke Klinik Fisioterapi Ratulangi Medical Centre Makassar selama penelitian berlngsung.

\section{Sampel}

Sampel penelitian adalah semua penderita nyeri pinggang bawah yang berkunjung ke Klinik Fisioterapi Ratulangi Medical Centre Makassar selama penelitian berlngsung yang memenuhi kriteria penelitian yang ditentukan peneliti. Jumlah sampel sebanyak 20 orang kemudian di random untuk kelompok I yaitu metode bugnet exercise sebanyak 10 orang dan kelompok II yaitu metode William fleksion exercise sebanyak 10 orang. Pengambilan sampel secara Accidental sampling selama periode penelitian dengan kriteria, yaitu :

1. Penderita nyeri pinggang bawah yang bukan akibat HNP

2. Berusia $>30$ tahun

3. Laki-laki dan perempuan

4. Bersedia ikut dakam penelitian ini

\section{Pengumpulan dan Analisis data}

Dilakukan dengan cara mencatat identitas penderita dan melakukan pemeriksaan fisioterapi dan melihat hasil pemeriksaan X-ray. Data nyeri diperoleh dengan mengukur aktualitas nyeri sebelum dan sesudah perlakuan. Pengukuran nyeri dengan menggunakan Visual analog scale (VAS) Pada tahap pelaksanaan setiap subjek penelitian diukur nilai nyerinya, kemudian pada kelompok perlakuan I diberikan metode Bugnet exercises dan pada kelompok perlakuan II diberikan Metode William Fleksion Exercises pada setiap subjek penelitian. setelah 8 kali pengobatan dari kedua kelompok perlakuan, diukur lagi nyerinya. Data yang diperoleh dianalisis dengan menggunakan uji Wilcoxon dan uji Mann-Whitney kemudian disajikan dalam bentuk tabel dan narasi. 


\section{Hasil Penelitian}

\section{Karakterisitik Responden Penelitian}

Pengumpulan data awal subjek penelitian di mulai tanggal 14 Juli 2015 dengan mencatat identitas pasien dan diagnosis pasien, sehingga didapatkan pasien yang mengalami Nyeri pinggang Bawah sebanyak 20 orang. Karakteristik subjek penelitian dapat dilihat berdasarkan usia dan jenis kelamin pada tabel dibawah ini.

Tabel 1.

Distribusi responden berdasarkan Usia di Klinik Fisioterapi RMC Makassar 2015

\begin{tabular}{|c|c|c|}
\hline Kelompok Usia & $\mathrm{f}$ & $\%$ \\
\hline $31-40$ Tahun & 10 Orang & $50 \%$ \\
$41-60$ Tahun & 10 Orang & $50 \%$ \\
\hline Jumlah & 20 Orang & $100 \%$ \\
\hline
\end{tabular}

Tabel di atas menunjukkan bahwa kelompok usia subjek penelitian 31 - 40 tahun dan usia 4160 tahun masing-masing $50 \%$.

Tabel 2.

Distribusi Responden berdasarkan Jenis Kelamin di Klinik Fisioterapi RMC Makassar 2015

\begin{tabular}{|c|c|c|}
\hline Jenis Kelamin & $\mathrm{f}$ & $\%$ \\
\hline Laki-Laki & 11 Orang & $55 \%$ \\
Perempuan & 9 Orang & $45 \%$ \\
\hline Jumlah & 20 Orang & $100 \%$ \\
\hline
\end{tabular}

Tabel di atas menunjukkan bahwa jumlah responden laki-laki lebih banyak dari pada responden perempuan yaitu laki-laki 11 orang ( $55 \%$ ).

2. Analisis aktualitas Nyeri pasien Nyeri pinggang Bawah sebelum dan sesudah pemberian IRR dan Bugnet exercises

Pengukuran aktualitas nyeri pada subjek penelitian yang mengalami nyeri pinggang bawah di lakukan dua kali dengan menggunakan VAS yaitu sebelum diberikan perlakuan IRR dengan bugnet exercises dan IRR dengan William fleksioan exercises. Setelah perlakuan diberikan sebanyak 8 kali kepada setiap subjek penelitian, maka segera dilakukan pengukuran nilai VASnya. Untuk lebih jelasnya dapat dilihat pada tabel 3 di bawah.

Tabel.3

Distribusi Nilai Aktualitas Nyeri Subjek penelitian sebelum dan sesudah pemberian IRR dengan Bugnet exercises

\begin{tabular}{|c|c|c|c|}
\hline \multirow{2}{*}{} & \multicolumn{3}{|c|}{ Nilai VAS kelompok I } \\
\cline { 2 - 4 } & Pretest & Posttest & Selisih median \\
\hline Median & 7.9500 & 3.00 & 4.95 \\
\hline SD & 0.34254 & 0.66173 & \\
\hline
\end{tabular}

Berdasarkan tabel di atas menunjukan adanya perubahan Median nilai VAS pasien nyeri pinggang bawah dari 7.9500 $\mathrm{cm}$ pada pretest menjadi $3,00 \mathrm{~cm}$ pada post test dengan selisih median $4,95 \mathrm{~cm}$ setelah diberikan IRR dan bugnet exercises. Dengan demikian pemberian intervensi IRR dengan bugnet exercises dapat menurunkan aktualitas nyeri pasien nyeri pinggang bawah.

Pada uji statistik juga diperoleh perubahan nilai aktualitas nyeri pasien 
nyeri pinggang bawah sebelum dan sesudah pemberian IRR dan Bugnet exercises secara signifikan. Untuk lebih jelasnya dapat dilihat pada tabel 4 di bawah ini.

Tabel 4.

Perbandingan Nilai Aktualitas Nyeri Subjek penelitian sebelum dan sesudah pemberian IRR dengan Bugnet exercises

\begin{tabular}{|c|c|c|c|c|c|}
\hline & \multicolumn{3}{|c|}{ Nilai VAS kelompok I } & \multirow{2}{*}{ Ket } \\
\cline { 2 - 4 } & Pretest & Posttest & Selisih median & p & \\
\hline Median & 7.9500 & 3,00 & 4.95 & 0,000 & $\mathrm{~S}$ \\
\hline
\end{tabular}

Keterangan : Wilcoxon test, $\mathrm{S}=$ signifikan

Hasil uji wilcoxon Test pada aktualitas nyeri akibat nyeri pinggang bawah sebelum dan sesudah pemberian IRR dan bugnet exercises menunjukkan perbedaan yang signifikan $(\mathrm{p}<0,05)$ dengan selisih median 4,95 .

3. Analisis Nilai Aktualitas Nyeri pasien nyeri pinggang bawah sebelum dan

\section{sesudah pemberian IRR dan William fleksion exercises.}

Pengukuran aktualitas nyeri sama dengan kelompok perlakuan I,yaitu dengan mengukur nilai VAS sebelum dan sesudah pemberian IRR dan William fleksion exercises. Untuk lebih jelasnya dapat pada tabel 5 di bawah ini.

Tabel 5

Distribusi Nilai Aktualitas Nyeri Subjek penelitian sebelum dan sesudah pemberian IRR dengan William Fleksion exercises

\begin{tabular}{|c|c|c|c|}
\hline \multirow{2}{*}{ Median } & \multicolumn{3}{|c|}{ Nilai VAS kelompok II } \\
\cline { 2 - 4 } & Pretest & Posttest & Selisih median \\
\hline SD & 7,900 & 3,3500 & 4,60 \\
\hline
\end{tabular}

Tabel di atas menunjukan perubahan rerata nilai VAS pasien nyeri pinggang bawah dari 7.900 pada pretest menjadi $3.3500 \mathrm{~cm}$ dengan selisih median 4.60 $\mathrm{cm}$ setelah diberikan IRR dan William fleksion exercises.

Pada Uji statistik juga diperoleh perubahan nilai aktualitas nyeri pinggang bawah sebelum dan sesudah pemberian IRR dan William fleksion exercises secara signifikan. Untuk lebih jelasnya dapat dilihat pada tabel 6. di bawah ini.

\section{perubahan nilai aktualitas nyeri 6}

Perbandingan Nilai Aktualitas Nyeri Subjek penelitian sebelum dan sesudah pemberian IRR dengan William flekion exercises

\begin{tabular}{|c|c|c|c|c|c|}
\hline \multirow{2}{*}{} & \multicolumn{3}{|c|}{ Nilai VAS kelompok II } & \multirow{2}{*}{ Ket } \\
\cline { 2 - 6 } & Pretest & Posttest & Selisih median & $\mathrm{p}$ & Kedian \\
& 7.900 & 3,3500 & 4,60 & 0,005 & $\mathrm{~S}$ \\
\hline
\end{tabular}

Keterangan : Wilcoxon test , $\mathrm{S}=$ signifikan

Hasil uji wilcoxon tes pada aktualitas nyeri akibat nyeri pinggang bawah sebelum dan sesudah pemberian IRR dengan William fleksion exercises menunjukkan perbedaan yang signifikan $(\mathrm{p}<0,05)$. 
3. Analisis Nilai Aktualitas Nyeri Pasien Nyeri pinggang bawah sesudah perlakuan antar kelompok I dan II

Untuk mengetahui hasil analisis aktualitas nyeri antar kelompok setelah diberikan perlakuan, maka dilakukan Uji
Independent T-test. Hasil Uji tersebut diperoleh nilai rerata kelompok I ( IRR dengan Bugnet exercises) dan kelompok II ( IRR dengan William Fleksion xercises) dapat terlihat pada tabel 7 di bawah ini

Tabel 7

Perbandingan Nilai Aktualitas Nyeri Subjek penelitian sesudah perlakuan Antar kelompok

\begin{tabular}{|c|c|c|c|c|}
\hline Perlakuan & Median & $\begin{array}{c}\text { Selisih } \\
\text { median }\end{array}$ & $\mathrm{p}$ & Ket \\
\hline $\begin{array}{c}\text { IRR dengan Bugnet } \\
\text { Exercises }\end{array}$ & 3.000 & 0,35 & 0,052 & TS \\
\hline $\begin{array}{c}\text { IRR dengan Wiliam } \\
\text { Fleksion Exercises }\end{array}$ & 3.3500 & & & \\
\hline
\end{tabular}

Keterangan : Mann Whitney test, TS = tidak signifikan

Hasil Mann Whitney Test aktualitas nyeri akibat nyeri pinggang bawah setelah perlakuan antar kelompok tidak menunjukkan adanya perbedaan yang signifikan ( $p>0,05)$. Jika dilihat dari perbedaan rerata nilai VAS sesudah perlakuan antar kelompok, maka kelompok yang diberikan IRR dengan William Fleksion Exercises mempunyai nilai median perubahan yang lebih besar yaitu $3.3500 \mathrm{~cm}$ dibanding kelompok perlakuan IRR dengan Bugnet exercises yaitu $3.000 \mathrm{~cm}$.

\section{Pembahasan}

\section{Karakteristik Subjek Penelitian}

Pada penelitian ini subjek penelitian terdiri dari 20 orang yang terdiri dari dua kelompok, yaitu kelompok yang diberikan IRR dengan Bugnet exercises sebanyak 10 orang dan kelompok yang diberikan IRR dengan William Flekson Exercises berjumlah 10 orang juga .Berdasarkan analisis hasil karakteristik subjek penelitian diperoleh data hasil penelitian bahwa subjek penelitian yang mengalami nyeri pinggang bawah adalah usia 31 sampai dengan 60 tahun. Data ini menunjukkan bahwa kejadian nyeri pinggang dapat dialami pada usia muda hal ini disebabkan oleh beberapa faktor diantaranya posisi dan sikap saat melakukan aktivitas sehari-hari baik di tempat kerja maupun di rumah. Menurut John E Murtagh (1997) pada usia 40 tahun ke atas telah mengalami proses degenerasi dimana segmen L4-L5 dan L5-S1 paling sering mengalami degenerasi yang sering menimbulkan nyeri pada pinggang.

2. Nilai aktualitas nyeri pasien Nyeri pinggang Bawah sebelum dan sesudah pemberian IRR dengan Bugnet Exercises

Berdasarkan data nilai aktualitas nyeri pada kelompok yang diberikan IRR dengan Bugnet exercises seperti pada tabel 3. dan tabel 4. terlihat bahwa terdapat perubahan nilai VAS sebelum dan sesudah pemberian perlakuan. Hal ini menunjukkan bahwa dengan pemberian IRR dan Bugnet exercises dapat menurunkan nyeri pasien. Keadaan ini dapat terjadi karena dengan metode latihan bugnet dilakukan dengan kontraksi isometrik secara general yang disertai dengan koreksi postur. Menurut Carolyn Kisner dan Lynn Allen Colby (1996) menyatakan bahwa kontraksi isometrik pada otot-otot erector spine yang kemuidan diikuti relaksasi dapat menurunkan nyeri dan spasme otot melali efek autogenic inhibisi. 
Selanjutnya Carolyn kisner dan Lynn Allen Colby ( 1996) mengemukakan bahwa ketika suatu otot berkontraksi sangat kuat, terutama jika ketegangan menjadi berlebihan maka ecara tiba-tiba kontraksi menjadi terhenti dan otot relaksasi. Relaksasi ini sebagai respon terhadap ketegangan yang sangat kuat, yang dinamakan dengan inverse stretch reflex atau autogenic inhibisi yang menyesuaikan dengan hukum kedua sherrigaton, yaitu jika otot mendapat stimulasi untuk berkontraksi, maka otot antagonis menerima impuls untuk relaksasi.pemberian bugnet exercise dengan aplikasi kontraksi isometrik dapat menghasilkan relaksasi otot melalui efek autogenic inhibisi sehingga lambat laun nyeri dan spasme akan menurun. Jika otot erector spine kembali rileks dan spasme menurun maka akan terjadi penurunan tekanan pada diskus pada lumbal dan tercipta aligment vertebra lumbal yang lumbal yang normal sehingga akhirnya nyeri akan menurun.

3. Nilai aktualitas nyeri pasien Nyeri pinggang Bawah sebelum dan sesudah pemberian IRR dengan William Fleksion exercises

Setelah dilakukan pengukuran nilai VAS pada subjek penelitian kelompok II yang mendaptkan intervensi IRR dengan William Fleksion exercise, maka dipeoleh hasil seperti pada tabel 5. dan 6. Ternyata terdapat penurunan nyeri pada 10 subjek penelitian sebelum dan sesudah intervensi. Hal ini sesuai dengan penelitian Setiasih (2012) bahwa metode William fleksion exercises dapa menurunkan nyeri pada pasien nyeri pinggang.

Ketika subjek penelitian diberikan metode William fleksion exercises, maka akan terjadi penguluran pada otot erector spine dan penguatan otot-otot abdominal. Ketika terjadi gerakan akan mempengaruhi kerja otot tipe I dan tipe II pada derah lumbal karena danya oksidasi dari kerja otot, dari kombinasi kerja otot tipe I dan II yang merupakan otot intermediate (fast oxidative glicolitic) tersebut maka akan mempengaruhi pembentukan energy dalam mitkondria sehingga mempengaruhi sistem transportasi oksigen yang akan memperbaiki sisten oksidasi, dengan demikian nyeri dapat berkurang dan endurance dapat meningkat (Wilmore dan Cosstill 1994.)

Menurut Carolyn Kisner dan Lynn Allen Colby (1996) ketika suatu otot terulur, maka akan terjadi respon neurofisiologi pada otot tersebut yang diatur oleh muscle spindle dan golgi tendon organ. Muscle spindle berfungsi untuk memonitor kecepatan dan durasi regangan/penguluran serta rasa terhadap perubahan panjang otot. Serabut muscle spindle dapat merasakan cepatnya suatu otot terulur. Serabut saraf afferent primer (tipe Ia) dan sekunder (tipe II) muncul dari muscle spindle dan bersinaps dengan alpha atau gamma motoneuron secara berurutan, dan memfasilitasi kontraksi dari serabut ekstrafusal dan intrafusal. Pada saat otot diregangkan secara pasif, maka pemanjangan awal terjadi pada sarkomer dan tension meningkat secara drastis dan setelah peregangan dilepaskan, maka setiap sarkomer akan kembali ke posisi resting length sehingga terjadi fleksibilitas otot dan ketika kontraksi otot yang kuat akan merangsang golgi tendon organ otot yang sama, kemudian menghasilkan respon inhibisi ke otot bersangkutan sehingga otot menjadi rileks.

Penelitian lain oleh Nila wahyudi di Universitas Udayana Bali (2012) ditemukan bahwa metode William fleksion exercises dapat mengurangi spasme otot-otot erector spine dan meningkatkan kekuatan otot abdominal dam mengurangi lordosis lumbal, sehingga tonus postural menjadi baik dan otot menjadi rileks.

\section{Nilai Aktualitas Nyeri Pasien Nyeri Pinggang Bawah sesudah perlakuan antar kelompok}

Pengukuran aktualitas nyeri setelah perlakuan antar kelompok dilakukan satu kali dengan menggunakan Visual analog scale. Hasil Uji menunjukkan bahwa tidak ada perbedaan yang bermakna terhadap aktualitas nyeri antara kelompok yang diberikan IRR dengan Bugnet exercises dan IRR dengan William Fleksion Exercises. Hasil analisis terhadap selisih rata-rata yang terjadi antar kelompok menunjukkan adanya perbedaan yang mana metode William fleksion exercises nilai rata- 
ratanya lebih tinggi dibandingkan metode bugnet exercises.

Hasil penelitian ini sesuai dengan penelitian Nila wahyudi ( 2012) bahwa metode William fleksion exercises dapat mengurangi spasme otot-otot erector spine dan meningkatkan kekuatan otot abdominal dam mengurangi lordosis lumbal, sehingga tonus postural menjadi baik dan otot menjadi rileks. Sedangkan Menurut Carolyn Kisner (1999), pemberian metode latihan dengan kontraksi dan relaksasi, akan menghasilkan efek pemanjang pada serabut collagennya dan secara teoritis latihan fleksi dapat mengurangi nyeri dengan cara mengurangi gaya kompresi pada sendi facet dan meregangkan extensor hip dan lumbal dan menguatkan otot-otot abdominal serta mengurangi hyperlordosis lumbal. Dengan demikian pasien-pasien yang mendapatkan intervensi William fleksion exercises akan mengalami penurunan nyeri yang pada akhirnya dapat meningkatkan mobilitas lumbal dan aktifitas fungsional yang berkaitan dengan mobilitas lumbal seperti yang dialami pada subjek kelompok I dan II.

\section{Kesimpulan}

1. Pemberian Infra red Rays dan Bugnet exercises mempunyai pengaruh terhadap perubahan nyeri penderita nyeri pinggang bawah dengan men $3.00 \mathrm{~cm}$.

2. Pemberian Infra red rays dan William Fleksion Exercises mempunyai pengaruh terhadap perubahan nyeri penderita nyeri pinggang bawah dengan mean $3.35 \mathrm{~cm}$

3 Infra red rays dengan William fleksion exercises mempunyai nilai rerata perubahan yang lebih besar yaitu 3,350 $\mathrm{cm}$ daripada kelompok perlakuan IRR dengan Metode Bugnet Exercise .

\section{Saran}

1. Dalam penelitian ini didapatkan tidak adanya perbedaan yang signifikan antara pemberian infra red Rays dan Bugnet Exercises dengan infra Red Rays dan William Fleksion Exercises pada pasien nyeri pinggang bawah, maka fisioterapis dalam menangani kasus tersebut disarankan menggunakan salah satu dari kedua metode tersebut untuk mengurangi nyeri pinggang bawah.

2. Perlu adanya penelitian lebih lanjut mengenai kedu metode tersebut dengan jumlah pasien yang lebih banyak dan metode penelitian klinis yang lebih baik, sehingga diperoleh metode yang terbaik.

\section{Ucapan terima kasih}

Terima kasih yang tak terhingga kami ingin sampaikan kepada :

1. Direktur Politeknik Kesehatan Kementerian Kesehatan Makassar

2. Ketua Jurusan Fisioterapi Poltekkes Kemenkes Makassar

3. Penanggung jawab Klinik Fisioterapi RMC Makassar

4. Kepala Unit Perpustakaan Poltekkes Makassar

5. Bapak dan Ibu Reviewer Penelitian Risbinakes

6. Bapak dan ibu dosen yang telah memberikan masukan dalam penyelesaian penelitian ini

\section{DAFTAR PUSTAKA}

Ann Thomson et.al, 1991. Tidy's Physiotherapy, Twelth Edition, Butterworth Heinemann, Oxford.

Cameron, Michelle. 2009. Physical Agents In Rehabilitation. St. Louis, Missouri: Saunders an Imprint of Elsevier.

Hari Basuki N, 2002, Dasar-dasar Statistik, Unair, Surabaya.

Hilary wadsworth, A.P.P. Chanmugan, 1988. Elektrophysical agent in physiotherapy, second edition, science press, Singapore

I.A. Kapandji, 1974, The Physiology of the joint, Volume 3, Churchill Livingstone, New York,

Jensen MP \& Karoly P. 2001. Hanbook of Pain Assessment, $2^{\text {nd }} \mathrm{Edn}, \quad \mathrm{New}$ York: Gulford Pres.

John E. Murtagh, Clive J. Kenna, 1997. Back Pain and Spinal Manipulation, Second Edition, Butterworth Heinemann, Oxfort, 
Kisner, Corolyn. Lynn Alen Colby, 1996; Therapeutic Exercise Foundations and Techniques, Third edition, F. A Davis Company, Philadelphia.

Louisa E.J. 1990. The International Association For the Study of Pain. Seatle: Washington University

Nancy Hamilton, Kathryn Luttgens, 2002. Kinesiology Scientific Basis of Human Motion, Mc Graw Hill, New York.

Navid, 2009. The Incidence of Back Pain, http://www.zimmerspine. eu/global/action, akses tanggal 25 Februari 2015.

Nugroho D.S.,Neurofisiologi Nyeri dari Aspek Kedokteran (Makalah disampaikan pada Pelatihan Penatalaksanaan Fisioterapi
Komperhensif Pada Nyeri), Surakarta, 7 - 10 Maret 2001.

Richard G. Fessler, 2007. Lower Back Pain; What You Need to know, University of Chicago, USA (http;//www.spineuniverse.com.)

Sastro Asmoro 2002, Dasar-dasar Metodologi Penelitian Klinis, ed.2, CV Sagung Seto, Jakarta

Suharsimi Arikunto, 1997, Prosedur Penelitian Suatu Pendekatan Paktek, Rineka Cipta Jakarta

Susan J. Hall, 2003. Basic Biomechanic, Fourth Edition, Mc Graw Hill, New York.

Wilmore JH and Castill DL, 1994, Essensial Exercises of Physiology, 2nd edition, Philadeplia, PA 